Estrada, M.E. y Viego, V. Reglamentación del uso del suelo y valorización inmobiliaria en los espacios costeros. El caso de Monte Hermoso (Buenos Aires, Argentina) Derecho y Ciencias Sociales. Mayo- Octubre 2019

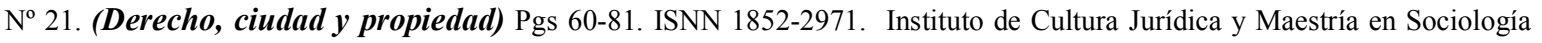
Jurídica. FCJ y S. UNLP

\title{
Reglamentación del uso del suelo y valorización inmobiliaria en los espacios costeros. El caso de Monte Hermoso (Buenos Aires, Argentina)
}

Land use regulations and real estate valorization in coastal spaces. The case of Monte Hermoso (Buenos Aires, Argentina)

María Emilia Estrada ${ }^{\circ}$ Valentina Viego $\bullet$

\section{Resumen}

Las normas que ordenan y regulan el uso del suelo se erigen sobre la función social y ecológica de la propiedad y, por ende, sus contenidos y alcances deberían hacer prevalecer el interés general por sobre el particular y la búsqueda de equidad entre quienes asumen costos y obtienen beneficios. El objetivo del artículo es ilustrar que dicha primacía es declarativa pero no necesariamente efectiva presentando el estudio de caso de la localidad de Monte Hermoso (provincia de Buenos Aires, Argentina), en la que, en al menos en dos oportunidades y bajo la conducción de distintos gobiernos, se aprobaron modificaciones de las normas de uso del suelo atendiendo a intereses particulares y con resultados asimétricos entre los agentes involucrados.

Palabras clave: función social de la propiedad, valorización inmobiliaria, ordenamiento del suelo, ambientes costeros

\begin{abstract}
The rules that regulate the use of land are based on the social and ecological function of property Hence, their contents and scope should focus on general over individual concerns and on the search for equity between those who assume costs and get benefits. Our aim is to show that this primacy is declarative but not necessarily effective by presenting the case study of Monte Hermoso (a city located in the SW of Buenos Aires province, Argentina). There, at least two urbanization projects under the direction of different administrations were approved modifying land use regulations. The modification of the rules reversed the prevalence principle (general over the particular) and entailed asymmetric results among beneficiaries.
\end{abstract}

Keywords: social function of property, real estate valorization, land use regulation, coastal spaces

\footnotetext{
- Maria Emilia Estrada.Doctora en Geografía por la Universidad Nacional del Sur. Profesora adjunta del Departamento deEconomía de la Universidad Nacional del Sur.emilia.estrada@uns.edu.ar.

- Valentina Viego. Doctora en Economía por la Universidad Nacional del Sur. Profesora adjunta del Departamento de Economía de la Universidad Nacional del Sur. Investigadora del Instituto de Investigaciones Económicas y Sociales del Sur (UNS, CONICET).vviego@,criba.edu.ar
}

Recibido: 28/2/2019. Publicable con correcciones: 16/8/2019. 
Estrada, M.E. y Viego, V. Reglamentación del uso del suelo y valorización inmobiliaria en los espacios costeros. El caso de Monte Hermoso (Buenos Aires, Argentina) Derecho y Ciencias Sociales. Mayo- Octubre 2019 No 21. (Derecho, ciudad y propiedad) Pgs 60-81. ISNN 1852-2971. Instituto de Cultura Jurídica y Maestría en Sociología Jurídica. FCJ y S. UNLP

\section{Reglamentación del uso del suelo y valorización inmobiliaria en los espacios costeros. El caso de Monte Hermoso (Buenos Aires, Argentina)}

María Emilia Estrada y Valentina Viego

\section{Introducción}

En la costa atlántica de la provincia de Buenos Aires el denominado turismo de "sol y playa" tiene distintos tipos de asentamientos y niveles de urbanización. El desarrollo turístico en esa región suele atraer inversiones que inciden en el despliegue de actividades preexistentes, como la pesca, y propician las construcciones sobre el espacio costero. Es habitual que este tipo de inversiones no tome en cuenta el impacto directo e indirecto de las dinámicas naturales del ecosistema marino, las restantes actividades económicas desplegadas en el territorio, los efectos colaterales negativos (falta de tratamiento de los residuos, agotamiento de recursos hídricos, etc.), el recurso paisajístico o los aspectos culturales y patrimoniales. Estos procesos han sido objeto de estudio de análisis académicos cuyas conclusiones advierten la falta de planificación territorial y la potencial desvalorización del destino, como resultados bastante generalizados de estas experiencias (Del Pozo y Bróndolo, 2002; Hernández, 2009; Benseny, 2011).

Las áreas costeras son zonas de transición entre el territorio y el mar de gran biodiversidad. Suelen sufrir fuertes presiones poblacionales por procesos de urbanización rápidos. En Argentina más del $15 \%$ de la población urbana vive en áreas costeras (a menos de $60 \mathrm{~km}$ del mar). ${ }^{1} \mathrm{~A}$ su vez, el destino turístico más importante es el costero y en muchos casos suele representar la mayor parte del ingreso de ciertas localidades.

La vulnerabilidad de las dunas costeras depende de las características del sistema: alto, ancho, estado de conservación, etc. y de la intensidad e impacto del evento (aumento del nivel del mar, tormentas, construcciones). Las más altas son más resistentes a crecidas del mar pero más susceptibles a erosión y viceversa. La dinámica de las dunas está determinada por disturbios naturales, que pueden ser recurrentes. Pero cuando aumentan en intensidad o frecuencia, tal como advierten los informes del Grupo Intergubernamental de Expertos sobre el Cambio Climático (GIECC) $(2001,2007)$ o cuando las dunas desaparecen por proyectos de urbanización, puede haber alteraciones significativas en la dinámica de la comunidad (Martínez y Psuty, 2004). Actualmente las disciplinas de la conservación del medio conciben como frágiles a las dunas ya que un shock pequeño (natural o inducido) puede conducir a cambios de largo plazo y progresivos (Carter, 1988) comprometiendo su diversidad natural fácilmente. Hay numerosa evidencia y estudios de este proceso en la zona costera del Mediterráneo en Europa (Tselentis et

\footnotetext{
${ }^{1}$ A nivel mundial esa proporción supera la mitad y experimenta una tendencia creciente.
} 
Estrada, M.E. y Viego, V. Reglamentación del uso del suelo y valorización inmobiliaria en los espacios costeros. El caso de Monte Hermoso (Buenos Aires, Argentina) Derecho y Ciencias Sociales. Mayo- Octubre 2019 No 21. (Derecho, ciudad y propiedad) Pgs 60-81. ISNN 1852-2971. Instituto de Cultura Jurídica y Maestría en Sociología Jurídica. FCJ y S. UNLP

al, 2007; Muñoz Vallés, Gallego Fernández y Dellafiore, 2011). Por ello, la conservación o, en su defecto, reposición de la vegetación autóctona permite estabilizar a la duna y amortiguar el impacto de shocks incontenibles.

A menudo, las áreas turísticas de costa forman parte de regiones con especies endémicas lo cual implica que el turismo ocurre en zonas ambientalmente frágiles ricas en biodiversidad. El turismo masivo en gran escala es una de las principales fuerzas detrás de la pérdida ecológica y destrucción. Ello ocurre porque la construcción asociada al desarrollo turístico (alojamientos, senderos, casas de fin de semana) provoca el mayor daño sobre la franja costera y ecosistemas marinos. Además, la atractividad del paisaje se ve afectada, lo cual puede a largo plazo impactar negativamente sobre el propio negocio turístico. Los impactos del turismo han afectado más negativamente a los sistemas costeros arenosos y costas de médanos en particular (Tzatzanis, Wrbka y Sauberer, 2003). Los senderos pedestres y motorizados sobre las dunas destruyeron vegetación e incrementaron la erosión (Williams et al, 2001). La recuperación de la duna depende de la oferta de sedimento en cada área y de la intensidad de la actividad humana. Con todo, como reconoce Westhoff (1966) no toda intervención humana sobre espacios más o menos naturales produce efectos netos negativos, en tanto constituye un elemento más del ecosistema, al igual que el clima, el sol o la hidrología. El criterio para valorar el sentido del impacto debería basarse en la inestabilidad que cada acción o proceso provoca sobre dicho ecosistema.

Los efectos para el territorio pueden ser de considerable magnitud, en tanto contribuye a todas las formas de contaminación (agua, desechos y atmósfera) con consecuentes costos económicos (inversiones para recuperar y encauzar cursos de agua, tratar residuos, etc) y además, dichos efectos pueden volverse contra la propia sustentabilidad del negocio turístico.

La sustentabilidad del desarrollo inmobiliario en áreas costeras debería estar garantizada por leyes y normas que arbitren los proyectos de urbanización con las posibilidades del medio territorial de absorber armónicamente dichas iniciativas sin comprometer a las poblaciones humanas, animales y vegetales. En esa creencia se asientan las disposiciones de ordenamiento territorial, que reconocen el principio de la función social y ecológica de la propiedad. Este criterio rector implica la prevalencia del interés general sobre el particular y la distribución equitativa de cargas y beneficios del suelo y su propiedad (Antik y Taller, 2007).

El objetivo de este trabajo es analizar si la función social y ecológica es efectivamente recreada o vulnerada en las normas y disposiciones de uso del suelo. El análisis se apoya en dos estudios de caso de la localidad de Monte Hermoso (provincia de Buenos Aires, Argentina). 
Estrada, M.E. y Viego, V. Reglamentación del uso del suelo y valorización inmobiliaria en los espacios costeros. El caso de Monte Hermoso (Buenos Aires, Argentina) Derecho y Ciencias Sociales. Mayo- Octubre 2019 No 21. (Derecho, ciudad y propiedad) Pgs 60-81. ISNN 1852-2971. Instituto de Cultura Jurídica y Maestría en Sociología Jurídica. FCJ y S. UNLP

La metodología utiliza fuentes documentales oficiales (leyes, decretos, ordenanzas, disposiciones, etc) y artículos periodísticos analizados desde una perspectiva crítica y fundamentada en la revisión de la literatura.

El artículo se organiza de la siguiente forma: luego de la presentación de la problemática ya realizada se resume el elenco de normas nacionales y provinciales que regulan el uso del suelo. Se incluyen también leyes específicas de conservación patrimonial. En la sección siguiente se describen dos proyectos de expansión del área urbana en la localidad de Monte Hermoso aprobados por el municipio en 2006 y 2016 y se analizan las modificaciones de la regulación vigente necesarias para la concreción de los proyectos. En la sección final se exponen las conclusiones.

\section{Las funciones social y ecológica de la propiedad: Leyes y normas que regulan el uso del suelo y del ambiente}

El ordenamiento territorial es un conjunto de deberes y derechos que estructuran los procesos de ocupación del suelo y edificación de las propiedades inmobiliarias. Según Antik y Taller (2007), dicho ordenamiento constituye la proyección en el espacio de la política pública, en función de las premisas constitucionales, socioeconómicas y culturales imperantes a partir de las cuales se establece el destino, uso, tráfico, transformación y utilización del suelo.

Como se señaló anteriormente, este corpus se funda en el reconocimiento de la función social de la propiedad, que implícita o explícitamente implica la prevalencia del interés general por sobre el particular y la distribución equitativa de costos y beneficios.

En Argentina, la función social de la propiedad fue admitida por primera vez en la Constitución de 1949, posteriormente derogada en 1955 bajo un gobierno dictatorial. Actualmente, tiene jerarquía constitucional, por la reforma de 1994, al declarar su adhesión a los tratados internacionales. Específicamente, por el artículo 21 de la Convención Americana de Derechos Humanos (también llamada Pacto de San José de Costa Rica) de 1969, que establece que "toda persona tiene derecho al uso y goce de sus bienes, pero el Estado puede subordinar ese uso y goce al interés social". En 14 Constituciones Provinciales también se reconoce este principio.

A su vez, la Constitución Nacional otorga a las provincias la competencia de dictar las leyes reguladoras del espacio físico y usos del suelo, estableciendo pautas y restricciones al derecho de propiedad. ${ }^{2}$ No obstante, según el sitio oficial Atlas ID $^{3}$ sólo Buenos Aires, Mendoza y Ciudad

\footnotetext{
${ }^{2}$ Para una discusión sobre las nociones subyacentes de propiedad y su correlato con el derecho, ver Levenzon (2012) y Perrone (2013).

${ }^{3}$ Disponible en: https://atlasid.planificacion.gob.ar/indicador.aspx?id=75. Recuperado el 14 de enero de 2019.
} 
Estrada, M.E. y Viego, V. Reglamentación del uso del suelo y valorización inmobiliaria en los espacios costeros. El caso de Monte Hermoso (Buenos Aires, Argentina) Derecho y Ciencias Sociales. Mayo- Octubre 2019

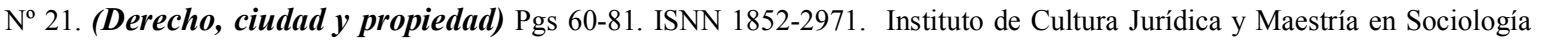
Jurídica. FCJ y S. UNLP

Autónoma de Buenos Aires poseen legislaciones específicas para orientar políticas territoriales que reconocen la función social de la propiedad y son relativamente recientes. ${ }^{4}$

El uso del suelo es la aptitud legal de un inmueble para desarrollar en él determinadas actividades. Las leyes que ordenan su uso establecen clasificaciones que habilitan ciertas funciones específicas asignadas. En términos generales, se reconocen 3 grandes clases de suelo: 1) urbano, el cual admite la edificación en los inmuebles de acuerdo a estándares y normas municipales; 2) de ensanche o complementario, que no admite edificación y es reservado por la administración pública para proyectos de ampliación urbana; y 3) suelo no urbanizable, donde los propietarios no pueden edificar en tanto se reconoce un valor productivo (agrícola, forestal, ganadero), paisajístico, histórico, cultural o ecológico o, alternativamente, por no ser apto para la vida humana dadas sus características físicas. ${ }^{5}$

En particular, la clasificación del suelo como "urbano" implica la dotación de cierta infraestructura: accesibilidad vehicular, suministro de servicios básicos (agua, electricidad, transporte, educación, etc.). Por ello, los cambios de clasificación de suelo de ensanche a urbano suelen ser acompañados por obras de apertura de calles y alumbrado público. Estos procesos pueden traccionar nuevas inversiones en infraestructura (gas, agua potable, transporte público, etc.) de acuerdo a las necesidades y recursos de los habitantes y de las perspectivas de rentabilidad de los operadores privados. ${ }^{6}$

Como toda norma, la legislación sobre el suelo es pasible de cambios y derogaciones y es, por ende, dinámica. Bajo regímenes democráticos, los cambios de las normas que rigen los usos del suelo deberían originarse en demandas de la comunidad, formales o informales, incorporando preocupaciones, intereses y necesidades de la población actual o potencial.

La evolución de las normas en Argentina se refleja, por ejemplo, en la incorporación en la Constitución Nacional, reformada en 1994, de cuestiones ambientales. Éstas tuvieron como antecedente el Pacto Federal Ambiental firmado en 1993 por los gobiernos provinciales y que nomina al Consejo Federal de Medio Ambiente (COFEMA) ${ }^{7}$ como instrumento válido para la regulación y coordinación de la política ambiental nacional. Este reconocimiento promulga el dictado de leyes y disposiciones tendientes a ampliar las áreas de protección. De este modo, se

\footnotetext{
${ }^{4}$ En la provincia de Buenos Aires el Decreto Ley 8.912 de 1977 y la Ley 14.449 de Acceso Justo al Hábitat, de 2012; en la provincia de Mendoza la Ley 8.051 de 2009 y en la Ciudad de Buenos Aires la Ley 2.930 de 2008.

5 Además, los espacios pueden ser parcelarios, circulatorios, edificatorios, verdes o públicos otorgando incluso distintos derechos a los propietarios (por ejemplo, la superficie edificable, restricciones de dominio, expropiación para obras de destino público, etc.).

${ }^{6}$ En general la inversión en infraestructura social suele ser llevada adelante por el Estado local o, eventualmente, provincial. No obstante, las obras de ampliación de servicios públicos suelen ser realizadas por las empresas prestadoras, usualmente con cargo (financiado o no) a los usuarios.

${ }^{7}$ El COFEMA fue formalmente constituido en agosto de 1990 y posee personería jurídica de derecho público.
} 
Estrada, M.E. y Viego, V. Reglamentación del uso del suelo y valorización inmobiliaria en los espacios

costeros. El caso de Monte Hermoso (Buenos Aires, Argentina) Derecho y Ciencias Sociales. Mayo- Octubre 2019 No 21. (Derecho, ciudad y propiedad) Pgs 60-81. ISNN 1852-2971. Instituto de Cultura Jurídica y Maestría en Sociología Jurídica. FCJ y S. UNLP

añade la función ecológica a la función social del suelo reconociendo, por ende, los derechos ambientales.

La Constitución Nacional establece en el artículo 41 que,

Todos los habitantes gozan del derecho a un ambiente sano, equilibrado, apto para el desarrollo humano y para que las actividades productivas satisfagan las necesidades presentes sin comprometer las de las generaciones futuras; y tienen el deber de preservarlo. El daño ambiental generará prioritariamente la obligación de recomponer, según lo establezca la ley. Las autoridades proveerán a la protección de este derecho, a la utilización racional de los recursos naturales, a la preservación del patrimonio natural y cultural y de la diversidad biológica, y a la información y educación ambientales. Corresponde a la Nación dictar las normas que contengan los presupuestos mínimos de protección, y a las provincias, las necesarias para complementarlas, sin que aquéllas alteren las jurisdicciones locales. (art. $41 \mathrm{CN}$ )

De este modo, por disposición constitucional aunque en términos muy amplios, el Estado se compromete a velar por el ambiente en todos sus niveles de gobierno, planteando un alcance muy abarcativo en su nivel de protección (Esaín y García Minella, 2013).

Según Drnas de Clément (2013), en este artículo quedan consagrados varios principios generales del derecho ambiental: la sostenibilidad, el deber de preservación que sienta la base del principio conservacionista (que se traduce en una mayor limitación de los derechos individuales); la responsabilidad ambiental, que implica la obligación de recomponer, y la responsabilidad funcional estatal de prevención/precaución y de provisión de información y educación.

Dicho marco general se completa con la Ley General del Ambiente 25.675, sancionada en 2002, que "establece los presupuestos mínimos para el logro de una gestión sustentable y adecuada del ambiente, la preservación y protección de la diversidad biológica y la implementación del desarrollo sustentable" (art. 1), por lo que sus disposiciones son de orden público y deben utilizarse para la interpretación y aplicación de la legislación ambiental en todo el país, no pudiendo las normas locales oponerse a ellas (art. $41 \mathrm{CN}$ y art. 5 ley 25.675).

Asimismo, esta ley establece en el artículo 4 los principios de la política ambiental (algunos ya enunciados en el artículo 41 de la CN, y coincidentes con los del derecho ambiental internacional (Drnas de Clément, 2013):

i) el de congruencia (compatibilidad de la legislación en las distintas esferas de gobierno);

ii) el de prevención (prioridad y atención integral de los problemas ambientales); 
Estrada, M.E. y Viego, V. Reglamentación del uso del suelo y valorización inmobiliaria en los espacios

costeros. El caso de Monte Hermoso (Buenos Aires, Argentina) Derecho y Ciencias Sociales. Mayo- Octubre 2019 No 21. (Derecho, ciudad y propiedad) Pgs 60-81. ISNN 1852-2971. Instituto de Cultura Jurídica y Maestría en Sociología Jurídica. FCJ y S. UNLP

iii) el precautorio (ante ausencia de información o certeza científica no se debe postergar la adopción de medidas para impedir la degradación del medio ambiente);

iv) el de equidad intergeneracional (se debe velar por el uso y goce apropiado del ambiente por parte de las generaciones presentes y futuras);

v) el de progresividad (los objetivos ambientales deberán ser logrados en forma gradual);

vi) el de responsabilidad (el generador de efectos degradantes, actuales o futuros, sobre el ambiente es responsable de los costos de las acciones preventivas y correctivas);

vii) el de subsidiariedad (el Estado Nacional tiene la obligación de colaborar y de participar en el accionar de los particulares en la preservación y protección ambientales);

viii) el de sustentabilidad (el desarrollo económico y social y el aprovechamiento de los recursos naturales no deben comprometer las posibilidades de las generaciones presentes y futuras);

ix) el de solidaridad (la Nación y los Estados provinciales serán responsables de la prevención y mitigación de los efectos ambientales transfronterizos);

$\mathrm{x}$ ) el de cooperación (los recursos naturales y los sistemas ecológicos compartidos deben ser utilizados en forma equitativa y racional y las emergencias ambientales de efectos transfronterizos serán desarrollados en forma conjunta).

De estos principios se puede establecer una distinción entre daño ambiental de carácter colectivo y el daño ambiental de carácter individual, aun cuando existen vacíos legales en cuanto a su recomposición (Cafferata, 2012).

Asimismo, en sus arts. 8, 9 y 10 la ley 25.675 enuncia que para el desarrollo de asentamientos humanos debe considerarse la vocación de cada zona o región, en función de los recursos ambientales y la sustentabilidad social, económica y ecológica. A su vez, el artículo 29 invoca normas del derecho civil, penal y administrativo (Cafferata, 2012).

Además, como ya se mencionó, la provincia de Buenos Aires cuenta con normativa que rige distintos aspectos del ordenamiento territorial, el uso del suelo y su protección, la conservación, mejoramiento y restauración de los recursos naturales y del ambiente, y el acceso justo al hábitat. El cuadro 1 sintetiza los principales aspectos. 
Estrada, M.E. y Viego, V. Reglamentación del uso del suelo y valorización inmobiliaria en los espacios costeros. El caso de Monte Hermoso (Buenos Aires, Argentina) Derecho y Ciencias Sociales. Mayo- Octubre 2019 № 21. (Derecho, ciudad y propiedad) Pgs 60-81. ISNN 1852-2971. Instituto de Cultura Jurídica y Maestría en Sociología Jurídica. FCJ y S. UNLP 
Estrada, M.E. y Viego, V. Reglamentación del uso del suelo y valorización inmobiliaria en los espacios costeros. El caso de Monte Hermoso (Buenos Aires, Argentina) Derecho y Ciencias Sociales. Mayo- Octubre 2019 No 21. (Derecho, ciudad y propiedad) Pgs 60-81. ISNN 1852-2971. Instituto de Cultura Jurídica y Maestría en Sociología Jurídica. FCJ y S. UNLP

Tal como puede apreciarse en la provincia algunas normativas han anticipado de alguna manera a las nacionales, tal es el caso del decreto ley 8.912 previendo los derechos ambientales (art. 2) o el decreto provincial 1.802 de Manejo Costero Integrado (MCI) de 2008. Esto contrasta con la situación a nivel nacional donde se carece de una regulación marco, ${ }^{8}$ donde las problemáticas en estos territorios son abordadas de forma heterogénea, dispersa e inconexa diluyendo las responsabilidades (Alvarez y Alvarez, 1984; Dadón et al, 2011; Boscarol, Fulquet y Preliasco, 2016).

Finalmente, tanto la normativa nacional como provincial reconocen que los daños o perjuicios ambientales son complejos de mensurar y de difícil reparación, afectando en alguna medida los principios de la política ambiental. De ahí la importancia de la adopción de medidas preventivas legalmente previstas, como la evaluación de impacto ambiental tanto en obras públicas como privadas.

\section{Inversiones inmobiliarias en la localidad de Monte Hermoso (provincia de Buenos Aires,} Argentina)

La localidad de Monte Hermoso tiene una superficie urbana estimada en 6,5 $\mathrm{km}^{2}$, rodeada por un área periurbana cubierta de dunas vegetadas o con coníferas implantadas. A su vez el partido de Monte Hermoso posee un frente costero de $32 \mathrm{~km}$ que se extiende en sentido Oeste - Este. Desde el punto de vista geográfico, el ambiente se describe como franja costera, área transicional entre tierra firme y el espacio marítimo.

Las costas marinas constituyen espacios dinámicos, complejos y fácilmente degradables, caracterizados por la interacción entre la tierra, el mar y la atmósfera, donde conviven múltiples actividades productivas, comerciales y residenciales, representando activos estratégicos para el desarrollo local y regional (Dadón, 2002; Dadón, 2010; Boscarol, Fulquet y Preliasco, 2016).

Estos ambientes son receptores del impacto de los diferentes usos del suelo de una extensa área espacial (grandes inversiones inmobiliarias y productivas, desagüe de cuencas y de efluentes urbanos e industriales, etc.) producto de la explotación y desarrollo poco ordenados/reglados y de otros fenómenos de alcance global como el cambio climático. Asimismo, lo acaecido en estos espacios no se restringe físicamente a ellos, sino que los efectos del desarrollo inmobiliario son transferidos a territorios circundantes gracias a la dinámica de factores físicos y biológicos, entre

\footnotetext{
${ }^{8}$ Por el momento sólo se cuenta con un documento inicial publicado en el año 2016, en sintonía con los compromisos multilaterales asumidos por el país (Agenda 21 y Río+20), que plantea ciertas líneas de trabajo básicas, tales como la de conseguir financiamiento para la elaboración y puesta en práctica de una Estrategia Federal de MCI.
} 
Estrada, M.E. y Viego, V. Reglamentación del uso del suelo y valorización inmobiliaria en los espacios costeros. El caso de Monte Hermoso (Buenos Aires, Argentina) Derecho y Ciencias Sociales. Mayo- Octubre 2019 № 21. (Derecho, ciudad y propiedad) Pgs 60-81. ISNN 1852-2971. Instituto de Cultura Jurídica y Maestría en Sociología Jurídica. FCJ y S. UNLP

los que se destaca el proceso de deriva litoral $^{9}$ y su incidencia en el proceso de formación del sistema de dunas (Dadón, 2002; Montserrat y Celsi, 2009; Dadón, 2010).

Los ambientes de dunas tienen múltiples funciones en el ecosistema costero: constituyen grandes reservorios naturales de arena, protegen a la costa de la erosión, intervienen en la formación de acuíferos mediante el filtrado y almacenamiento en profundidad del agua de lluvia y ofrecen un hábitat para el desarrollo de comunidades de animales y vegetales en la costa (Rumbold, Davis y Perretta, 2001; Montserrat, Celsi y Fontana, 2012). A las playas de arena se les suele atribuir similares servicios ecológicos (Schlacher et al., 2007; McLachlan y Brown, 2006).

Las dunas constituyen geoformas frágiles y su alteración por efectos naturales o inducidos puede dar lugar a cambios progresivos y de largo plazo, comprometiendo la diversidad natural costera y sus funciones. Es por esto, que desde ámbitos académicos y ambientalistas se demanda una norma nacional de MCI.

El frente costero de dunas de Monte Hermoso tiene una extensión estimada de $11 \mathrm{~km}$. El aporte de arena para la formación de playas depende únicamente de los procesos de deriva litoral, específicamente de las dunas localizadas al oeste del partido. Con todo, estos aportes resultan insuficientes para mantener el equilibrio de las playas urbanas debido a la periodicidad de tormentas y sudestadas, además de la progresiva desaparición de dunas originada en la extensión de la urbanización.

Varios trabajos señalan que la notable expansión inmobiliaria en zonas costeras en diversas partes del globo no responde tanto a un incremento genuino y sostenido del turismo sino a operaciones especulativas con el suelo (Mazon y Aledo, 2005; Barrantes Reynolds, 2011). Las consecuencias más concretas de esta orientación de la inversión no basada en elementos observables y estables son dos: por un lado, la baja tasa de efectivización de los proyectos (expresada en el porcentaje alcanzado en el mediano plazo) y, por otro, el hecho de que la mayor parte de las edificaciones es utilizada pocos días al año, incluso en plena temporada.

Monte Hermoso no escapa a esta tendencia. Desde principios de los 90 la localidad ha sido receptora de proyectos inmobiliarios de gran envergadura que inmovilizan gran parte del suelo urbano y del ambiente natural. Uno de ellos es la urbanización denominada Monte Hermoso del Este, iniciada a principios de la década de 1990, y que en 2009 anexó una nueva etapa de expansión conocida como Aldea del Este. Esta segunda fase trajo nuevas alteraciones costeras

\footnotetext{
${ }^{9}$ La deriva litoral o costera consiste en el transporte de sedimentos a lo largo de la costa. Por un lado, el sedimento es empujado hacia la orilla por el reflujo que mueve la arena o la gravilla en el ángulo de la dirección del viento predominante; y por otro lado, el caudal de agua vuelve al mar de manera perpendicular a la línea de costa en función de la gravedad. De esta forma, el transporte de los sedimentos sigue la forma de un "serrucho". Este proceso juega un rol fundamental en la evolución de la costa e influencia numerosos aspectos del sistema costero, tales como la formación de dunas, la fauna y la flora costera, las que a su vez presentan ciclos a lo largo del año.
} 
Estrada, M.E. y Viego, V. Reglamentación del uso del suelo y valorización inmobiliaria en los espacios costeros. El caso de Monte Hermoso (Buenos Aires, Argentina) Derecho y Ciencias Sociales. Mayo- Octubre 2019 № 21. (Derecho, ciudad y propiedad) Pgs 60-81. ISNN 1852-2971. Instituto de Cultura Jurídica y Maestría en Sociología Jurídica. FCJ y S. UNLP

(apertura de caminos litorales, desaparición de médanos frontales) que han sido documentadas ya por otros autores (Di Martino et al, 2007; Espasa, Fittipaldi y Michalijos, 2017). Si bien no se dispone de estadísticas que reflejen la evolución de los permisos de edificación otorgados por el municipio, el Anuario Estadístico de 2014 elaborado por la Dirección Provincial de Estadística informa que en 2013 el municipio aprobó la construcción de 69.627 nuevos $\mathrm{m}^{2}$, ubicando al distrito en el último cuartil de la distribución de $\mathrm{m}^{2}$ cada mil habitantes del conjunto de municipios bonaerenses. ${ }^{10}$ Las disparidades de las cifras entre municipios reflejan, en parte, el carácter especulativo y rentístico que toma la actividad de la construcción. Los puntos que atraen inversiones inmobiliarias no están exclusivamente ligados al negocio turístico, sino también a los procesos de periurbanización de áreas urbanas, que ocurren de manera selectiva por procesos de diferenciación territorial y su consecuente valorización.

Se presentan aquí dos casos de proyectos de extensión del área urbana que implicaron modificaciones en la clasificación de usos del suelo en la localidad, ambos con impacto ambiental diferencial que aún no han sido analizados por la literatura. Al final de esta sección se ofrece un análisis de conjunto sobre las perspectivas que abren ambas iniciativas.

\section{a) Caso "Las Lomas"}

El emprendimiento denominado "Las Lomas" se localiza en el acceso a la localidad en cercanías al camino sinuoso y es considerado oficialmente como barrio cerrado. La inversión se concretó a partir de la desafectación por parte del municipio de las parcelas 17ak, 17bx, 17ab y 17by del "área complementaria" y su agregación a la zona urbanizable residencial (Ordenanza HCD 1.559/2006, modificada marginalmente luego por la Ordenanza HCD 1.727/2008). El proyecto inmobiliario implica el loteo de 408 terrenos en un predio de 51 ha, ofertados a inversores en valores entre 15 mil y 25 mil dólares cada uno (Danieli, 2006; La Nación, 11 de noviembre de 2006). El emprendimiento se promocionaba como un complejo cerrado con infraestructura deportiva de entretenimiento (canchas de básquet, tenis, vóley, etc.), restaurantes, piscinas, espacios recreativos para niños, alojamientos. Los desarrolladores dotarían de gas, agua potable y electricidad a los lotes (La Nación, 11 de noviembre de 2006).

Lo llamativo es que la venta de los terrenos se inició en febrero de 2006 y el cambio de zonificación fue aprobado por las autoridades locales ocho meses después, aún sin contar con la

\footnotetext{
${ }^{10}$ Una inspección de los Anuarios Estadísticos que publica el organismo oficial provincial de estadísticas revela que no todos los municipios informan periódicamente los permisos de construcción otorgados. De todos modos, el ratio entre el promedio de $\mathrm{m}^{2}$ permisados entre 2010-2014 y la población arroja una media de $2.900 \mathrm{~m}^{2} / 1.000$ habitantes y una mediana de $674,3 \mathrm{~m}^{2} / 1.000$ habitantes. En Monte Hermoso ese ratio es de $10.713,5 \mathrm{~m}^{2} / 1.000$ habitantes, casi cuadriplicando la media provincial y mucho más la mediana.
} 
Estrada, M.E. y Viego, V. Reglamentación del uso del suelo y valorización inmobiliaria en los espacios costeros. El caso de Monte Hermoso (Buenos Aires, Argentina) Derecho y Ciencias Sociales. Mayo- Octubre 2019 No 21. (Derecho, ciudad y propiedad) Pgs 60-81. ISNN 1852-2971. Instituto de Cultura Jurídica y Maestría en Sociología Jurídica. FCJ y S. UNLP

debida autorización del órgano provincial. La Provincia aprobó esa modificación de usos del suelo recién en noviembre de 2011 (Decreto 1.824/2011), ${ }^{11}$ sobre el hecho consumado. En otros términos, los lotes comenzaron a ser vendidos y edificados antes de que el gobierno local modificara el status del suelo y de que las autoridades provinciales lo aprobaran.

Dos años después de la puesta en marcha (julio de 2008) llevaban vendidos sólo 55 lotes (13\%) (La Nueva, 1 de julio de 2008). Esto muestra que o bien se trata de inversiones de muy baja recuperación (y, por ende, su impacto sobre el empleo corre idéntica suerte) o el negocio se asienta en la adquisición de macizos que luego de lotearse y por efecto de la promoción se valorizan en la venta. Esta segunda opción implica que el desarrollador no busca invertir directamente en el mercado turístico sino en el inmobiliario, basado en la captación de fondos y en la valorización de activos. Así, entonces no es extraño encontrar proyectos turísticos que generan excedente de plazas combinado con precios de alquileres persistentemente elevados.

No se han reportado para el caso de Las Lomas impactos medioambientales de magnitud, pero su desarrollo colisiona con el principio de la función social de la propiedad; en tanto el precio de mercado del suelo se incrementa sustancialmente para el desarrollador (adquirente del macizo cuando gozaba del status previo en la legislación y oferente luego de lotes), beneficiando los intereses particulares por sobre los generales. Hay evidencia de que la especulación inmobiliaria tiene un impacto sobre el bienestar colectivo, en tanto los movimientos de precios en un segmento (el beneficiado por los nuevos usos potenciales del suelo) se traslada al resto, obstaculizando el acceso a la vivienda de sectores populares (Jiménez Romera y Fernández Ramírez, 2014). Si bien no se dispone de información suficiente que permita estimar el impacto de este emprendimiento sobre los precios de las propiedades, la magnitud de la especulación se puede apreciar comparando los precios iniciales y actuales de los terrenos: en 2006 se ofrecían entre 15 y 25 mil dólares (Danieli, 2006); en julio de 2018 los precios rondaban los 33 mil dólares $^{12}$ lo cual implica una valorización mínima de 2,3\% anual en dólares, superior a la de cualquier otro activo. El obstáculo al acceso a la vivienda en la localidad de Monte Hermoso impulsado por el boom inmobiliario es documentado por Fittipaldi et al (2015).

Considerando la relación derecho-territorio en particular, este emprendimiento se contrapone al art. 5 de la ley 11.723 que establece la obligatoriedad de la planificación del crecimiento urbano, lo cual alcanza al emplazamiento de nuevos barrios como indica el Anexo II. Por su parte, de

\footnotetext{
${ }^{11}$ El texto completo de las ordenanzas y del decreto provincial que aprueba la modificación se encuentra disponible en el siguiente link: http://www.gob.gba.gov.ar/intranet/digesto/PDF/D1824-11.pdf, recuperado el 13 de febrero de 2019.

${ }^{12}$ Recuperado de los siguientes sitios: www.bahiapropiedades.com, www.properati.com, el 22 de julio de 2018.
} 
Estrada, M.E. y Viego, V. Reglamentación del uso del suelo y valorización inmobiliaria en los espacios costeros. El caso de Monte Hermoso (Buenos Aires, Argentina) Derecho y Ciencias Sociales. Mayo- Octubre 2019 № 21. (Derecho, ciudad y propiedad) Pgs 60-81. ISNN 1852-2971. Instituto de Cultura Jurídica y Maestría en Sociología Jurídica. FCJ y S. UNLP

haber estado vigente la ley 14.449 (Acceso Justo al Hábitat), esta inversión hubiese confrontado notoriamente con sus objetivos.

\section{Mapa 1. Localización de las áreas complementarias afectadas por ordenanzas municipales. Monte Hermoso.}

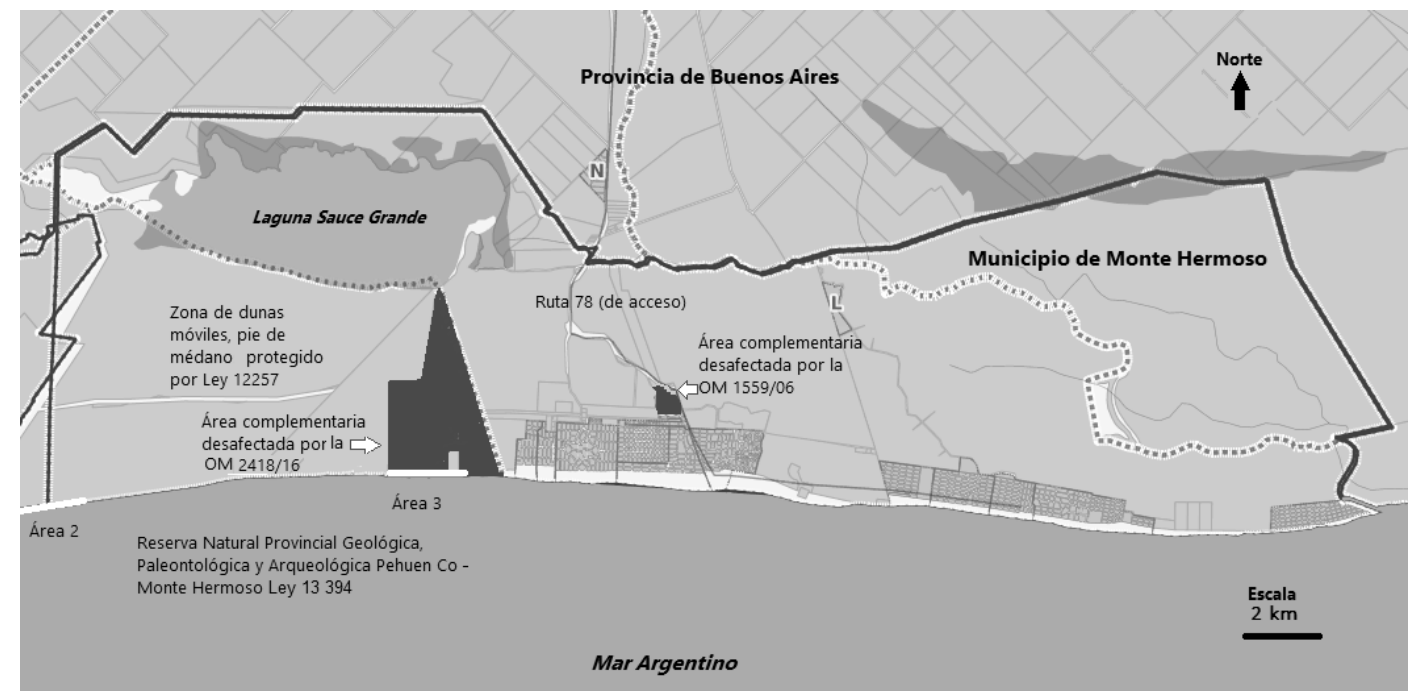

Fuente: elaboración propia en base a cartografía de la Agencia de Recaudación de la Provincia de Buenos Aires (ARBA) y a las Ordenanzas 1.559/2006 y 2.418/2016

\section{b) Caso lindante a "Reserva Natural"}

A principios de enero de 2016, el Concejo Deliberante (en adelante, HCD) aprobó en sesión extraordinaria la extensión del área urbana mediante la desafectación del inmueble localizado en la parcela 1.050c de la partida 126-016730-4 de la denominada "área complementaria", es decir no urbanizable (Ordenanza HCD 2.418/2016).

Además, en el mismo acto el gobierno dispuso que la parcela constituye una "zona de desarrollo y consolidación prioritaria” y establece la nueva zonificación del predio según el detalle expuesto en el Cuadro $2 .^{13}$

El cambio de uso del suelo para dicho inmueble dispuesto por el gobierno local habilita el loteo de 933 parcelas contiguas a la denominada “Área 3” de la Reserva Natural Provincial Geológica, Paleontológica y Arqueológica Pehuen Co - Monte Hermoso. La reserva es un área protegida incluida en la lista indicativa que Argentina propuso a la UNESCO en 2014, en tanto posee características de valor excepcional. La decisión que finalmente tome ese organismo multilateral depende de la concreción de una serie de tareas que permitan garantizar el status de la reserva

\footnotetext{
${ }^{13}$ El texto completo de la ordenanza se encuentra disponible en http://www.montehermoso.gov.ar/ftp_muni/computos/ORDENANZAS/Ordenanzas_2418_2016.pdf, recuperado el 10 de noviembre de 2018.
} 
Estrada, M.E. y Viego, V. Reglamentación del uso del suelo y valorización inmobiliaria en los espacios

costeros. El caso de Monte Hermoso (Buenos Aires, Argentina) Derecho y Ciencias Sociales. Mayo- Octubre 2019 No 21. (Derecho, ciudad y propiedad) Pgs 60-81. ISNN 1852-2971. Instituto de Cultura Jurídica y Maestría en Sociología Jurídica. FCJ y S. UNLP

como área protegida, lo cual requiere la elaboración de un plan de manejo. Hasta la fecha en que el municipio dispuso la modificación en los usos del suelo vigentes definidos para esa zona, dicho plan se encontraba aún sin concluir y la decisión tomada en enero de 2016 aleja aún más su futura concreción.

Los sitios arqueológicos, como los que conforman la reserva y su área lindante (zona buffer o de amortiguación), son bienes públicos protegidos por la ley nacional 25.743 (decreto reglamentario 1.022/2004). La protección oficial también es reconocida por normales provinciales, como la ley 10.907, que pretende promover la conservación del ambiente y los elementos de carácter patrimonial que lo integran. Su conservación no sólo tiene una dimensión ambiental sino también científico y cultural; el reconocimiento de este otro aspecto motivó su inclusión como Lugar Histórico Nacional (ley 27.220/2015) y se encuentra, por ello, bajo el dominio de la Comisión Nacional de Museos y de Monumentos y Lugares Históricos dependiente del Ministerio de Cultura nacional (ley 12.665/1940).

La decisión del gobierno de Monte Hermoso implica la urbanización de parte de la zona buffer de la reserva, espacio clave y requisito crítico para la elaboración de planes de manejo de áreas protegidas que aspiran a constituirse en patrimonio mundial. Si el área de amortiguación no está definida o está afectada por otras actividades (como las previstas en la ordenanza de 2016), la protección de la reserva se encuentra amenazada.

La parcela afectada por el cambio de clasificación del suelo tiene una superficie total de 507 ha, se localiza al oeste de la localidad de Monte Hermoso, separada del área urbana por una formación dunar de $500 \mathrm{~m}$ de frente costero. La decisión del gobierno local habilita la edificación sobre algo más del 15\% de la superficie total del terreno y admite la ocupación del frente marítimo desde $150 \mathrm{~m}$ de la línea de ribera. La zona afectada es un espacio de transición entre ambientes marinos y continentales, en la que intervienen aspectos demográficos, económicos, ecológicos y geográficos representando un ambiente frágil y cambiante. El 
Estrada, M.E. y Viego, V. Reglamentación del uso del suelo y valorización inmobiliaria en los espacios costeros. El caso de Monte Hermoso (Buenos Aires, Argentina) Derecho y Ciencias Sociales. Mayo- Octubre 2019

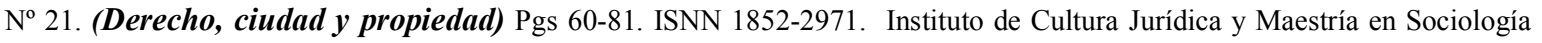
Jurídica. FCJ y S. UNLP

desarrollo de esta urbanización implica la erradicación de la franja de dunas en formación, lo que fortalecerá los procesos erosivos de las playas del área urbana actual, en conflicto con los objetivos declarados del Ministerio de Ambiente y Desarrollo Sustentable, que desea instalar el concepto de "manejo costero" a partir de una serie de programas para el desarrollo sustentable de los recursos y ambientes costeros, equiparando el criterio ambiental a los criterios económicos y sociales (Boscarol, Fulquet y Preliasco, 2016).

Además, la urbanización de esa parcela afectaría a la función ecológica de escurrimiento del agua de lluvia, por las tareas de nivelación de calles y de impermeabilización del suelo para las construcciones. ${ }^{14}$ A ello se suma la erosión de la playa y de los médanos provocada por la mayor circulación de turistas.

En suma, la decisión del HCD de Monte Hermoso de 2016 colisiona con los objetivos y disposiciones de las leyes 11.723 y 12.257 .

Por otra parte, considerando que la capacidad de alojamiento actual de Monte Hermoso se ubica en unas 24.600 plazas $^{15}$ y tomando en cuenta el área afectada y la densidad máxima admitida en cada zona, la modificación de la reglamentación sobre usos del suelo ampliaría en más del 80\% la capacidad actual de alojamiento de la localidad (Cuadro 3). Aún cuando la ocupación efectiva alcance niveles menores a los máximos permitidos, el impacto sobre el terreno es innegable.

\footnotetext{
${ }^{14}$ Este efecto no ha sido mensurado ni pronosticado para el caso analizado en tanto se carece de estudios de impacto. No obstante, trabajos previos en la localidad advierten este fenómeno atribuido a la urbanización, que produce impermeabilizacion antrópica (Celsi et al, 2010; Celsi, 2017; Di Martino et al, 2017).

${ }^{15}$ La capacidad de alojamiento surge de adicionar las plazas de la infraestructura hotelera y parahotelera relevadas por Lalli (2012) al tamaño medio de las viviendas que carecen de residentes permanentes registradas en el último censo de población y viviendas. Si bien la estimación no es precisa, ofrece un orden de magnitud para evaluar la escala de los proyectos inmobiliarios analizados.
} 
Estrada, M.E. y Viego, V. Reglamentación del uso del suelo y valorización inmobiliaria en los espacios costeros. El caso de Monte Hermoso (Buenos Aires, Argentina) Derecho y Ciencias Sociales. Mayo- Octubre 2019 $\mathrm{N}^{\circ}$ 21. (Derecho, ciudad y propiedad) Pgs 60-81. ISNN 1852-2971. Instituto de Cultura Jurídica y Maestría en Sociología Jurídica. FCJ y S. UNLP

En tanto el proyecto habilita el desarrollo de un área residencial de ocupación estacional dirigida a segmentos de ingresos medios y altos ello, se contrapone con la ley 14.449 toda vez que contribuye a elevar el precio medio de las viviendas de la localidad, dificultando el acceso para la población local y fomentar la especulación.

\section{c) Elementos subyacentes en los proyectos de expansión urbana y desarrollo inmobiliario}

Los dos estudios de caso presentados arriba poseen elementos en común que permiten proponer la hipótesis de un "modus operandi" de los grandes proyectos inmobiliarios que se desarrollan en áreas costeras, al menos en base a la evidencia ofrecida por Monte Hermoso:

- La modificación de normas no fue precedida por estudios de impacto ambiental, tal como lo estipula el artículo 5b de la ley 11.723/1995. Invariablemente la habilitación de proyectos inmobiliarios de gran envergadura no se encuentra precedida por estudios sobre la calidad y stock de los acuíferos locales y anima inversiones que pueden comprometer la oferta actual y futura del recurso acuífero.

- Los argumentos esgrimidos (en ordenanzas y en los medios de comunicación ${ }^{16}$ ) que fundamentan los actos de gobierno para modificar normas y reglamentos que ponen en riesgo las funciones social y ecológica de la propiedad realzan las inversiones y puestos de trabajo que se generarían en la etapa de construcción, elementos que en el corto y mediano plazo sólo se manifiestan débilmente. Generalmente este tipo de proyectos suele tener impactos netos negativos sobre el medioambiente (por la desaparición de ambientes naturales con funciones ecológicas), pero la insistencia en la generación de empleo y movilización de recursos locales parecería contrabalancear las consecuencias negativas. Conviene destacar algunos elementos que permiten matizar el impacto sobre el empleo. Según datos del Consejo Mundial de Viajes y Turismo, en Argentina, cada empleo directo del sector genera 2,81 puestos totales (WTTC, 2018). En el caso local, esta cifra puede ser algo menor ya que gran parte de la afluencia turística se conforma por familias, que se instalan en viviendas particulares sin servicios (limpieza, desayuno, etc.) y suelen tener un patrón de gasto moderado (elaboración de comidas en las viviendas, alto porcentaje de jóvenes con presupuesto limitado, etc.). El impacto sobre el empleo del sector turístico, aún cuando parece ser mayor a otras actividades productivas, tiene peculiaridades que disminuyen su potencial. En primer lugar, tiene un fuerte componente estacional; si bien la creación de empleo directo durante la construcción de

\footnotetext{
${ }^{16}$ Danieli (2006).
} 
Estrada, M.E. y Viego, V. Reglamentación del uso del suelo y valorización inmobiliaria en los espacios

costeros. El caso de Monte Hermoso (Buenos Aires, Argentina) Derecho y Ciencias Sociales. Mayo- Octubre 2019 N $^{\circ}$ 21. (Derecho, ciudad y propiedad) Pgs 60-81. ISNN 1852-2971. Instituto de Cultura Jurídica y Maestría en Sociología Jurídica. FCJ y S. UNLP

infraestructura de alojamiento y accesos puede ser considerable, una vez concluida la etapa de inversión, los empleos generados ocurren sobre una base "ad hoc" o en función de la demanda; se trata de un sector donde la mano de obra representa un costo enteramente variable. Así, se contrata personal cuando hay afluencia de turistas y se libera mano de obra en períodos de menor ocupación. Segundo, los empleos del sector turístico son de baja remuneración y calidad, elevada informalidad, y de escasa participación en decisiones (Hernández, 2009). Esto ocurre porque las ocupaciones afectadas típicamente al turismo son servicio doméstico (mucamas, mantenimiento de instalaciones), atención al público en expendio de comidas, venta ambulante en sector de playa. Hay una tendencia a requerir personal calificado en recepción de turistas en alojamientos hoteleros, pero su incidencia es baja en comparación al resto.

- Acceso desigual a la regulación del suelo: por un lado, los grandes proyectos gozan de permisividad (cuando no de exenciones impositivas, subsidios a ciertos gastos, etc) mientras que los pequeños inversores no logran iguales condiciones y suelen enfrentar trabas burocráticas para concretar sus iniciativas. En este caso, la Ordenanza HCD 2.428/2016 da cuenta de este trato preferencial al declarar a la zona como de "desarrollo prioritario".

\section{Reflexiones finales}

Las normas de usos del suelo tienen por objeto ordenar la forma en que la población ocupa el suelo a fin de preservar distintas funciones sociales. Este ordenamiento incluye también al derecho ambiental y a las normas de preservación del patrimonio natural, de más reciente vida en la historia del derecho sobre el espacio.

En este marco, las autoridades de la localidad de Monte Hermoso (provincia de Buenos Aires) aprobaron en 2006 y 2016 cambios en los usos del suelo con el propósito de admitir el loteo de macizos de suelo y habilitar la edificación de viviendas de uso residencial destinadas a sectores de altos ingresos. En conjunto los dos proyectos favorecidos implican una ampliación equivalente al $20 \%$ de la superficie urbana actual, lo cual refleja su envergadura y sus potenciales impactos sobre el ecosistema social y natural.

Los marcos regulatorios de usos del suelo son sólo uno de los aspectos que intervienen en la ocupación que efectivamente tiene lugar en el territorio, en tanto la denominada "función social de la propiedad" coexiste con otra función crítica para las sociedades de clase, como la acumulación de medios de producción (y una de sus variantes, la especulación). Por ende, dichas 
Estrada, M.E. y Viego, V. Reglamentación del uso del suelo y valorización inmobiliaria en los espacios

costeros. El caso de Monte Hermoso (Buenos Aires, Argentina) Derecho y Ciencias Sociales. Mayo- Octubre 2019 No 21. (Derecho, ciudad y propiedad) Pgs 60-81. ISNN 1852-2971. Instituto de Cultura Jurídica y Maestría en Sociología Jurídica. FCJ y S. UNLP

normas no están exentas de las tensiones que se experimentan en la implementación de políticas de gestión, conservación, uso privado y usos públicos del mismo.

Una primera reflexión sobre la relación entre normas y el uso efectivo del suelo que se deriva de los estudios de caso es que cuando las acciones de individuos particulares y atomizados violentan la función social de la propiedad, suelen prevalecer las normas. Cuando, en cambio, la acumulación por parte de individuos con acceso privilegiado al poder pone en riesgo dicha función social, las normas son incumplidas, modificadas o exceptuadas. Esta apreciación relativiza la capacidad del derecho escrito de limitar las acciones individuales para ajustarse a un orden social, en la medida en que dicho derecho se inscribe en relaciones sociales de producción organizadas en torno a clases sociales con intereses contrapuestos.

\section{Bibliografía}

Alvarez, J. A. y Alvarez, S. M. (1984). Conceptos básicos sobre manejo costero. Buenos Aires: Instituto de Publicaciones Navales.

Antik, A. y Taller, A. (2007). La necesidad de incorporar los principios rectores del ordenamiento territorial en la futura Reforma Constitucional Santafesina. Ponencia presentada en IV Congreso Argentino de Administración Pública Sociedad, Gobierno y Administración. Buenos Aires [en línea]. Disponible en: http://www.asociacionag.org.ar/pdfcap/4/Antik\%20\%20Taller.doc

Barrantes Reynolds, M. P. (2011). The expansion of "real estate tourism" in coastal areas: its behaviour and implications. Recreation and Society in Africa, Asia and Latin America, 2(1).

Benseny, G. B. (2011). Valorización turística y transformación territorial costera en la Provincia de Buenos Aires (Argentina). Párrafos Geográficos 10(2), 110-129.

Boscarol, N., Fulquet, G. y Preliasco, G. (2016). Aportes para una estrategia federal en manejo costero integrado: estado de la gestión costera en el Litoral Atlántico Argentino. Ciudad Autónoma de Buenos Aires: Ministerio de Ambiente y Desarrollo Sustentable [en línea]. Disponible en: https://www.argentina.gob.ar/sites/default/files/libro_manejo_costero_web-bajaresolucion $0 . p d f$

Cafferata, N. (2012). Doctrina del día: reformulación del principio de progresividad a 10 años de la ley 25.675 general de ambiente. Avances y novedades. Revista de Derecho Ambiental, Abeledo Perrot [en línea]. Disponible en: 
Estrada, M.E. y Viego, V. Reglamentación del uso del suelo y valorización inmobiliaria en los espacios costeros. El caso de Monte Hermoso (Buenos Aires, Argentina) Derecho y Ciencias Sociales. Mayo- Octubre 2019 № 21. (Derecho, ciudad y propiedad) Pgs 60-81. ISNN 1852-2971. Instituto de Cultura Jurídica y Maestría en Sociología Jurídica. FCJ y S. UNLP

http://thomsonreuterslatam.com/2012/11/doctrina-del-dia-reformulacion-del-principio-deprogresividad-a-10-anos-de-la-ley-25675-general-del-ambiente-avances-y-novedades/

Carter, R.W.G. (1988). Coastal Environments. London: Academic Press.

Celsi, C. E., Mc Lean, H. D., Yessi, A. y Triches, M. (2010). Dunas Costeras de la Pampa Austral: Biodiversidad, Ecología y Conservación entre el Río Quequén Salado y el Balneario Pehuen Co. Buenos Aires: Fundación de Historia Natural Félix de Azara.

Celsi, C. E. (2017). La vegetación de las dunas costeras pampeanas. En: Athor, J. y Celsi, C. E. (Eds.) La Costa Atlántica de Buenos Aires. Naturaleza y Patrimonio Cultural (pp.116-138). Buenos Aires: Fundación de Historia Natural Félix de Azara.

Dadón, J. R. (2002). El impacto del turismo sobre los recursos naturales costeros en la costa pampeana. En: Dadon, J. R. y Matteucci, S. D. (Eds.) Zona Costera de la Pampa Argentina (101-121) [en línea]. Buenos Aires: Lugar Editorial. Disponible en: http://www.ecologiamarina.com.ar/down/impa.pdf

Dadón, J. R. (2010). Manejo costero en la República Argentina. Congreso Red Ibermar [en línea]. Disponible en: http://municipioscosteros.org/contenidos/22102013104611.pdf, recuperado el 24/02/2019.

Dadón, J. R., Boscarol, N., Lara, A., Lebrero, C., Fèbre, R. y Lasta, C. (2011). Sostenibilidad de la zona costera argentina: avances en el manejo costero. En: Barragán Muñoz, J.M. (Coord.) Manejo Costero Integrado y Política Pública en Iberoamérica: Propuestas para la acción (pp. 171-190). Cádiz: Red Ibermar (CYTED).

Del Pozo, O, y Bróndolo, M. (2002). Unidades de paisaje como instrumentos de ordenamiento territorial. Sector costero Monte Hermoso (Pcia. de Buenos Aires). Revista Universitaria de Geografia, 11, 91-120.

Di Martino, C., Albouy, E.R., Marcos, A. y Bastianelli, N. (2017). La expansión urbana del balneario Monte Hermoso, provincia de Buenos Aires, Argentina: problemática ambiental. Ponencia presentada en IV Congreso Internacional Científico y TecnológicoCONCYT 2017. Universidad Nacional de Quilmes [en línea]. Disponible en:

https://digital.cic.gba.gob.ar/handle/11746/6758

Drnas de Clément, Z. (2013). El rol normativo de los principios generales. En: Derecho Ambiental en la Provincia de Buenos Aires [en línea]. Buenos Aires: Abeledo Perrot. Disponible 
Estrada, M.E. y Viego, V. Reglamentación del uso del suelo y valorización inmobiliaria en los espacios costeros. El caso de Monte Hermoso (Buenos Aires, Argentina) Derecho y Ciencias Sociales. Mayo- Octubre 2019 № 21. (Derecho, ciudad y propiedad) Pgs 60-81. ISNN 1852-2971. Instituto de Cultura Jurídica y Maestría en Sociología Jurídica. FCJ y S. UNLP

en:

http://www.acaderc.org.ar/doctrina/principios-generales-del-derecho-

ambiental/at_download/file

Espasa, L., Fittipaldi, R. y Michalijos, M.P. (2017). Impacto del turismo y del modelo neoliberal en las transformaciones urbanas de ciudades menores: el caso de Monte Hermoso, Buenos Aires.

Argentina. PAMPA [en línea], (15), 107-129. Disponible en: https://doi.org/10.14409/pampa.v15i15.6604

Esaín, J. A. y García Minella, G. (2013). Derecho Ambiental en la Provincia de Buenos Aires. Buenos Aires: Abeledo Perrot.

Fittipaldi, R., Mira, S., Espasa, L. y Facchini, M. E. (2015). Monte Hermoso: una población en crecimiento. Los efectos de la migración interna e internacional. Contribuciones Cientificas GAEA [en línea], 27, 65-78. Disponible en: http://www.gaea.org.ar/contribuciones/Contribuciones2015/Fittipaldi-Mira-Espasa.pdf

GIECC - Grupo Intergubernamental de Expertos sobre el Cambio Climático (2001). Cambio Climático: La base cientifica. Programa de las Naciones Unidas para el Medio Ambiente.

GIECC - Grupo Intergubernamental de Expertos sobre el Cambio Climático (2007). Cambio Climático: Impactos, Adaptación y Vulnerabilidad. Programa de las Naciones Unidas para el Medio Ambiente.

Hernandez, F. M. (2009). Reflexiones sobre las problemáticas asociadas al desarrollo turístico en el litoral marítimo bonaerense: paisaje, tierras y trabajo. Revista de Estudios Marítimos y Sociales, 2(2), 147-158.

Jimenez Romera, C. y Fernandez Ramirez, C. (2014). Casas sin gente, gente sin casas: el fracaso del modelo inmobiliario español. Revista INVI [en línea], 29(82), 133-155. Disponible en: https://dx.doi.org/10.4067/S0718-83582014000300005

Lalli, C. M. (2012). El turismo residencial desde la demanda turística. El caso Monte Hermoso. Tesina de Licenciatura en Turismo. Departamento de Geografía y Turismo, Universidad Nacional del Sur [en línea $]$ Disponible en: http://repotur.yvera.gob.ar/bitstream/handle/123456789/125/TESIS\%20CARMEN\%20MAR201 2.pdf? sequence $=1 \&$ is Allowed $=y$

Levenzon, F. (2012). La función social de la propiedad en términos de derechos humanos; implicaciones para la reforma del Código Civil. Revista Argentina de Teoría Jurídica [en línea], 12. Disponible en: http:/www.pensamientocivil.com.ar/system/files/levenzon2.pdf 
Estrada, M.E. y Viego, V. Reglamentación del uso del suelo y valorización inmobiliaria en los espacios costeros. El caso de Monte Hermoso (Buenos Aires, Argentina) Derecho y Ciencias Sociales. Mayo- Octubre 2019 № 21. (Derecho, ciudad y propiedad) Pgs 60-81. ISNN 1852-2971. Instituto de Cultura Jurídica y Maestría en Sociología Jurídica. FCJ y S. UNLP

La Nacion (11 de noviembre de 2006). El primero en Monte Hermoso. La Nación / Propiedades. Disponible en: https://www.lanacion.com.ar/propiedades/el-primero-en-monte-hermoso$\underline{\text { nid856958, }}$ recuperado el 23 de noviembre de 2018.

Danieli, M. (05 de febrero de 2006). Se viene el country Las Lomas. La Nueva / La región. Disponible en: https://www.lanueva.com/nota/2006-2-5-9-0-0-se-viene-el-country-las-lomas, recuperado el 03 de enero de 2019.

La Nueva (1 de julio de 2008). Manu recorrio sus inversiones inmobiliarias en Monte Hermoso. La Nueva / La ciudad. Disponible en: https:/www.lanueva.com/nota/2008-7-1-11-49-0--manurecorrio-sus-inversiones-inmobiliarias-en-monte-hermoso, recuperado el 12 de diciembre de 2018.

Martínez, M. L, y Psuty, N. P. (2004). Coastal Dunes. Ecology and Conservation. Berlin: Springer.

Mazon, T. y Aledo, A. (2005). El dilema del turismo residencial: ¿turismo o desarrollo inmobiliario. En: Turismo residencial y cambio social: nuevas perspectivas teóricas y empíricas (Eds.) (pp. 13-30). Alicante: Aguaclara.

McLachlan, A. y Brown, A. C. (2006). The ecology of sandy shores. Burlington, MA: Academic Press.

Montserrat, A. L y Celsi, C. E. (2009). Análisis regional de la costa pampeana austral en el marco del sistema de áreas protegidas y caracterización de un área clave como reserva en el partido de Coronel Dorrego. BioScriba, 2(1), 1-23.

Montserrat, A. L., Celsi, C. E. y Fontana, S. L. (2012). Coastal dune vegetation of the southern Pampas and its value for conservation. Journal of Coastal Research, 28(1), 23-35.

Muñoz Vallés, S., Gallego Fernández, J. B. y Dellafiore, C. M. (2011). Dune vulnerability in relation to tourism pressure in central Gulf of Cádiz (SW Spain), a case study. Journal of Coastal Research, 27(2), 243-251.

Perrone, N. M. (2013). Artículo 21: Derecho a la Propiedad Privada. En: Alonso Regueira, E. (Coord.) La Convención Americana de Derechos Humanos y su proyección en el Derecho Argentino (pp. 355-369). Buenos Aires: La Ley.

Rumbold, D. G., Davis, P. W. y Perretta, C. (2001). Estimating the effect of beach nourishment on Caretta caretta (loggerhead sea turtle) nesting. Restoration Ecology, 9(3), 304-310. 
Estrada, M.E. y Viego, V. Reglamentación del uso del suelo y valorización inmobiliaria en los espacios costeros. El caso de Monte Hermoso (Buenos Aires, Argentina) Derecho y Ciencias Sociales. Mayo- Octubre 2019 $\mathrm{N}^{\circ}$ 21. (Derecho, ciudad y propiedad) Pgs 60-81. ISNN 1852-2971. Instituto de Cultura Jurídica y Maestría en Sociología Jurídica. FCJ y S. UNLP

Schlacher, T., Dugan, J., Schoeman, D., Lastra, M., Jones, A., Scapini, F., McLachlan, A. y Defeo, O. (2007). Sandy beaches at the brink. Diversity and Distributions, 13(5), 556-560.

Tselentis, B., Prokopiou, D., Bousbouras, D. y Toanoglou, M. (2007). Environmental impacts caused by the tourist industry in Elafonisos Island and the Neapoli district, Greece. WIT Transactions on Ecology and the Environment, 106, 375-385.

Tzatzanis, M., Wrbka, T. y Sauberer, N. (2003). Landscape and vegetation responses to human impact in sandy coasts of Western Crete, Greece. Journal for Nature Conservation, 11(3), 187195.

Westhoff, V. (1966). The ecological impact of pedestrian equestrian and vehicular traffic on vegetation. En: Vers un nouveau type de relations entre l'homme et la nature en région tempérée. Towards a new Relationship of Man and Nature in Temperate Lands (pp. 218-223). Morges, Switzerland: UNESCO.

Williams, A. T., Alverinho Dias, J., Novo, F. G., Garcia Mora, M. R., Curr, R. y Pereira, A. (2001). Integrated coastal dune management: checklists. Continental shelf research, 21(18/19), 1937-1960.

WTTC - World Travel and Tourism Council (2018). Travel \& Tourism Economic Impact 2018 Argentina. Disponible en https://www.wttc.org/economic-impact/country-analysis/countryreports/, recuperado el 20/02/2019. 